\title{
Darío Ruiz Gómez, PARA DESCUBRIR LA CIUDAD*
}

\author{
Darío Ruiz Gómez, \\ for Discovering the City
}

Andrés Vergara Aguirre ${ }^{1}$

\footnotetext{
* Cómo citar esta entrevista: Vergara Aguirre, A. (2022). Darío Ruiz Gómez, para descubrir la ciudad. Estudios de Literatura Colombiana 50, pp. 181-193. DOI: https://doi. org/10.17533/udea.elc.n50a10

1 https://orcid.org/0000-0002-5304-6550 andres.vergaraa@udea.edu.co

Universidad de Antioquia, Colombia
}

Editores: Andrés Vergara Aguirre, Christian Benavides Martínez

Recibido: 12.10 .2021

Aprobado: 14.12.2021

Publicado: 17.01.2022

Copyright: (2022 Estudios de Literatura Colombiana. Este es un artículo de acceso abierto distribuido bajo los términos de la Licencia Creative Commons AtribuciónNo comercial - Compartir igual 4.0 Internacional

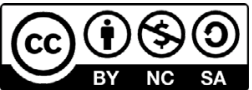

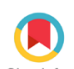
Check for
updates

Darío Ruiz Gómez (Anorí, Antioquia, 1936) es novelista, cuentista, poeta, ensayista, crítico de arte,

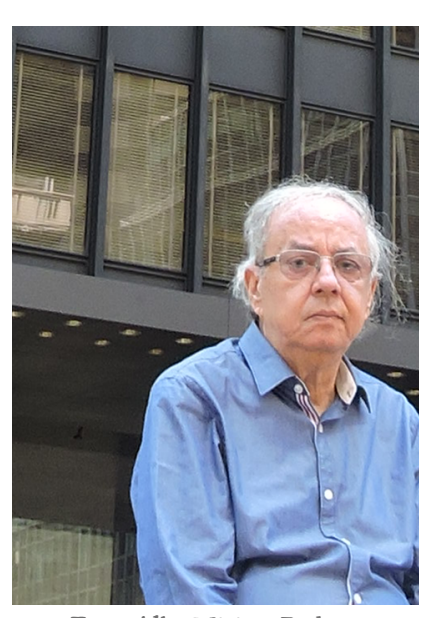

Foto: Alba Miriam Bedoya crítico literario, urbanista, investigador y profesor universitario. Un humanista, en síntesis. Se graduó en España en 1961 en la Escuela Oficial de Periodismo. Y en esa misma época hizo estudios de Estética y urbanismo, en tiempos del franquismo, y aclara que alzó su voz contra la dictadura. Tanto que fue expulsado de España, aunque también aclara que desde que llegó allá por primera vez, en 1958, siempre ha estado estrechamente vinculado a ese país, donde en sus años de ejercicio del periodismo fundó el suplemento cultural del periódico Hierro, de Bilbao. En Colombia nunca volvió a ejercer el periodismo de tiempo completo, pero sí ha colaborado en distintos medios, entre ellos El Tiempo, El Espectador, El Colombiano, y escribió una columna de opinión en El Mundo du- 
rante treinta años. Y su oficio como columnista le ha exigido mantenerse alerta, como en una especie de insomnio, dice, "donde a medida que un país se adentra en nuevos abismos es necesario hacer claridad sobre todo lo que ha sido sobrepasado inevitablemente y saludar lo que del fondo del abismo se rescata como expresión purificada de nueva vida" (Ruiz Gómez, 1993, p. 309).

De su carrera como escritor dan testimonio sus obras, que ya conforman un listado amplio en distintos géneros, como los libros de cuentos Para que no se olvide su nombre (1967), La ternura que tengo para vos (1982), Para decirle adiós a mamá (1983), Sombra de rosa y vino (1999), Crimenes municipales (2009) y Cuentos de la Estación Villa (2014), y las novelas Hojas en el patio (1979), En voz baja (1999) y Las sombras (2014). También es autor de numerosos libros de ensayo sobre arte, arquitectura, urbanismo, entre ellos De la razón a la soledad (1981), Trabajo de lector (2003) y Diario de ciudad (2005). Entre sus libros de poesía se cuentan A la sombra del ángel (1990) y La muchacha de la leyenda (2001). Algunos de sus cuentos y poemas han sido traducidos al inglés, al francés, al árabe y al alemán. En 2011 fue presentado en el Instituto Cervantes de Berlín su antología de cuentos traducida al alemán Bei den Heiden - En tierra de paganos-, editado en 2011 en Zurich y el cual tuvo una buena recepción crítica en Alemania. En la nota de solapa el editor concluye que "El arte de Darío Ruiz Gómez es mostrar no solo el camino de una ciudad, una sociedad al infierno, sino también el rostro humano del infierno" (Ruiz Gómez, 2011).

El profesor Darío se jubiló de su cátedra de Historia de Arquitectura Moderna y de Teorías del Espacio en la Facultad de Arquitectura de la Universidad Nacional de Colombia sede Medellín, aunque él aclara que sigue siendo profesor, por siempre. $\mathrm{Y}$ es cierto. Esto se nota en cada conversación, porque sin proponérselo siempre termina dando una clase, en nuestro caso de literatura y de la vida. La erudición le brota, sino por los poros, sí en cada afirmación, sin artificios. En estos años de jubilado sigue entregado con disciplina al oficio de escribir.

En su discurso, de una asombrosa vitalidad a sus 85 años, siempre resalta su apertura de pensamiento. En sus relatos tempranos ya expresaba un interés especial por darles protagonismo a las mujeres, como lo resalta Umberto Valverde, en una época en la que el lenguaje inclusivo todavía no se había puesto de moda: "En los cuentos de Darío Ruiz Gómez hay una línea coherente entre sus temáticas y personajes. Por ejemplo, hay una preocupación especial por el tratamiento de la mujer. Aspasia, Sandalia, Margarita, 
Amalia, María Eugenia, Luz de Estella, Ofelia, Elena, son algunos de sus nombres [...] siempre encontramos una sutil manera de penetrar su interioridad, en su dimensión psicológica, en su oculto desmoronamiento" (Valverde, 1996, p. 9).

En sus relatos adquieren protagonismo los derrotados, los seres infames como diría Foucault; a esos seres que nunca fueron mostrados ni nombrados, él busca darles rostros y nombres. Pero el principal personaje de su narrativa, el que aparece de manera constante, es la ciudad, con sus ruidos, sus olores, sus gritos, sus días y sus noches, sus vaivenes. Una ciudad que a cada instante se transforma también, cumpliendo con la máxima heraclitiana, como en este pasaje del cuento "Los ecos de la noche" - del volumen La ternura que tengo para vos, cuya primera edición es de 1966-, donde podemos ver cómo los automóviles, como la ciudad, adquieren vida y carácter en sus representaciones metafóricas:

Oían en la noche el ruido rápido de los automotores, de las llantas sobre el asfalto, esa serie de ruidos peculiares de la máquina, su modo de anunciarse entre la noche solitaria. Como un animal que puja o hace deliberadamente alarde de su fuerza: podían ser amarillos o verdes o verdes-amarillos o rojos-amarillos o de cualquier color posible. Con las vísceras macizas, oliendo a grasa nueva, esos cuerpos intrincados, sabios, inexplicables, con la apariencia de peces, centelleantes como tiburones, o chatos, serios, de gesto grave de voz ronca, señores aristocráticos (Ruiz Gómez, 1996, p. 8I).

A la ciudad, él la define como "el gran invento de la humanidad porque significa dejar atrás la servidumbre del campo, la fatalidad de la naturaleza y entrar en una compleja red donde aparecen los otros, donde la relación humana establece límites y descubre fronteras imprevistas. Es el horror, pero también, la poesía, tal como lo dimensiona Walter Benjamin en su retrato del Baudelaire de París" (Triviño, 2009).

Cuando se embarcó por primera vez rumbo a España, reconoce, ya había sentido el llamado de la literatura, la cual tiene la misión, según afirma, de mostrar el estrellarse de los seres contra la realidad, y esta clave de la modernidad "es lo que le da grandeza al verdadero arte, a la verdadera novela como fruto de la escritura, y no como producto del marketing de las grandes editoriales". Y precisamente, el tomar distancia de las exigencias de un mercado editorial le permitió desarrollar una obra más autónoma frente a los estereotipos incentivados por las grandes editoriales, según lo afirma Andrés Ruiz-Olaya (2017), pues ello

[...] le permite entonces contemplar críticamente la realidad que vive y que desea retratar sin concesiones como la forma más elevada de un compromiso social que no se restringe a un programa ideológico o a una agenda política. De esta forma la mirada crítica se nutre de su actividad intelectual como urbanista, ligando su obra narrativa a su indagar crítico de la realidad urbana y social, donde confluyen la ética, la estética y la política (p. iso). 
Darío también reconoce que el cine ha ejercido una influencia muy importante en su vida, y podemos sospechar que en gran parte su descubrimiento de la ciudad le llegó a través de las películas, desde que se aficionó a ellas en su adolescencia, y a la lectura de las críticas de cine, cuando todavía cursaba el bachillerato en el colegio San Carlos. Y si uno se sienta a conversar con él sobre los tiempos de su juventud, muy probablemente evocará la época en que pasaba las tardes en el café Miami —en el cruce de Junín con Caracas, precisará - con sus amigos, entre ello Carlos Gaviria, Gonzalo Arango y Jaime Jaramillo Panesso, heredados de su breve incursión como estudiante de derecho antes de abordar el Américo Vespucio, en el que haría su primera travesía rumbo a España en 1958, cuando emprendió la aventura de aquel viaje en compañía de su amigo Enrique Molina, y gracias a la complicidad de un tío que le pagó el tiquete, según relata.

\section{Maestro Darío, usted estudió periodismo en Madrid. ¿Qué lo llevó a estu- diar este oficio? ¿Esta formación tuvo alguna trascendencia en su carrera como académico y como escritor?}

Ya el periodismo no existe, pero desde el siglo xix en Francia su consolidación supone la aparición de un público pensante que acepta o dialoga con las ideas que los grandes escritores como Zola le proponen, caso del escándalo Dreyfus y la réplica a la intolerancia del patrioterismo francés. ¿Qué hubiera sido de Camus o de Mauriac sin sus columnas de opinión mediante las cuales convocaron a los grandes debates ideológicos? El pensamiento de Ortega y Gasset se hizo desde un periódico y hoy la columna de opinión de grandes pensadores sigue siendo un género literario que tiene sus propias normas. Entrar a la Escuela Oficial de Periodismo de Madrid fue adentrarme en la reflexión sobre lo que supone el pensamiento y el oficio de saber relatar con el criterio debido un hecho social, un aspecto de la vida cotidiana. La era digital es la era del analfabetismo y de la incapacidad para escribir, es decir para contar con una narrativa que acontece ante el gran público en una espacialidad y en una temporalidad del simulacro. No estudié Comunicaciones sino ese periodismo crítico necesario en cualquier sociedad que quiere mantener sus libertades. Estudié a la vez Estética y Urbanismo porque quien no trate de entender a los personajes y a los factores que todo proceso urbano conlleva está incapacitado para penetrar en la complejidad de una narrativa 
urbana y de sus protagonistas. Fuera de mi trabajo en el Hierro de Bilbao nunca he trabajado en un periódico, pero hace 32 años mantengo mi columna de opinión y sigo siendo profesor universitario.

Según leí en alguna parte, en su grado de periodismo tuvo que estrechar la mano de Francisco Franco. ¿Cómo recuerda hoy ese momento y, sobre todo, como recuerda la experiencia de vida en la España de aquella dictadura, entre 1958 y 1961 ?

Al terminar un postgrado sobre Información y Documentación se me dijo que había sido escogido con otros diez estudiantes para una recepción que haría Francisco Franco, Jefe de Gobierno de España, en El Prado. Durante casi dos horas que duró el acto, Franco, un anciano, permaneció de pie sin inmutarse. Luego de pronunciar unas breves palabras fuimos desfilando y dándole un saludo de mano. Hay una foto que recoge el instante en que el joven Darío saluda a un Jefe de Estado, algo que la policía del pensamiento trata de convertir en un supuesto apoyo a una dictadura contra la cual me pronuncié siempre en contra, haciendo parte de un grupo de intelectuales católicos como José Luis Aranguren, figura insigne de la lucha por las libertades, teniendo en cuenta aquellos consejos de Brecht en "Diez maneras de decir la verdad en tiempos de opresión”. ¿Sabe usted que salí de España por problemas políticos que comenzaron en Bilbao, y que después de diez años la democracia levantó esas sanciones? ¿No ha visto mi foto saludando en el Palacio de Oriente a los Reyes de España cuando se le dio el Premio Cervantes a la gran pensadora María Zambrano? ¿No ha sabido de mi estrecha amistad con los intelectuales que renovaron la democracia española?

Usted como creador y como intelectual ha sido muy prolifico. Novela, cuento, poesía, crítica literaria, ensayo, pero también columnista y estudioso de diversos temas que abarcan desde la arquitectura, el urbanismo, la teoría del espacio y el arte hasta asuntos políticos, sociológicos y filosóficos, entre otros. ¿Cuál considera que ha sido la clave para esa esa obra tan diversa y tan prolífica?

Mi bachillerato en el colegio San Carlos fue la clave de mi formación: geografía, literatura, psicología, filosofía, religión..., o sea que ya sabíamos a través de grandes 
textos como los de Bayona Posada quiénes eran Mallarmé o Verlaine, y en una época sin perturbaciones como la mala televisión todo el mundo leía a Víctor Hugo, a Sue, a Zola, a Ibsen, a Goethe, a Rubén Darío, lecturas que refrendaban los grandes suplementos literarios dedicados a la cultura universal. En 1957 en Movimiento, una publicación que editamos un grupo de amigos, apareció un artículo mío sobre la novela, y allí cito a Thomas Mann, Hesse, Katherine Mansfield, etc., a quienes las grandes editoriales argentinas publicaban entonces. ¿Por qué mi cuento "Aspasia", escrito en 1958, acusa la influencia de Pavese? Nací en el Humanismo Occidental y soy un intelectual humanista enfrentado a los totalitarismos que tratan de destruirlo. Para saber del proceso urbano de Medellín estudié el pensamiento de Olano y el pragmatismo de James, la filosofía de san Agustín y de santo Tomás, de Heidegger y Sartre, de Romano Guardini y de Maritain, estudié a Francastel y a Argan...

\section{¿Podemos preguntarle al Darío Ruiz Gómez escritor cuál considera que ha sido su principal obra o su principal aporte a la literatura colombiana?}

Las estructuras que plantea hoy el narcotráfico como dominio de los territorios urbanos no es la misma que aquella de Pablo Escobar y otros capos reconocibles y capaces de recurrir a la más demencial de las violencias copiando los métodos y estructuras de la Cosa Nostra. Hoy son más sutiles y se camuflan en el hecho de la globalización de los capitales y de que para los grandes sistemas financieros no existe escrúpulo alguno respecto al origen de los capitales que reciben, y que las rentas ilegales les producen inauditas ganancias. ¿Dónde está narrada por los escritores y escritoras jóvenes la derrota de la clase obrera y de la cultura popular, de los desempleados convertidos en esclavos de las bandas? ¿Quiénes han sido los cronistas de las verdaderas rebeliones musicales nuestras que son un logro de alcance mundial? Perdóneme, pero yo he escrito En tierra de paganos y Crimenes municipales, obras literarias definitivas en este salto cualitativo de una narrativa que los novelistas más jóvenes redujeron a folclor urbano, a testimonios sin mayor alcance. ¿Me hablaban al oído los muchachos de Pavese o de Pasolini encontrándose con su tragedia? Por lo menos hay, sin embargo, talentos narrativos jóvenes que ya son la esperanza de que se imponga esta estética del desarraigo, del miedo, del desvarío de estas clases derrotadas, la sórdida amargura de las muchachas y los muchachos que se suicidan, como nos lo recuerda Mark Fisher en Los fantasmas de mi vida, donde analiza muy bien estas derrotas de la clase obrera, 
estos sufrimientos. Reconozco a esos escritores nuevos, o mejor esas nuevas escrituras desde las cuales, sobrepasando el facilismo del sicariato, de la violentología, hablan desde las voces no reconocidas, desde las gentes que nunca fueron mencionadas. Por lo demás, la proliferación de territorios que permanecen bajo las leyes de las bandas nos muestra una ciudad sin centro, fragmentada, otra ciudad sin nombre.

\section{Estamos en una época de gran proliferación de escritores de muy diversas tendencias. ¿Cómo percibe este fenómeno contemporáneo?}

Proliferan escritores y escritoras porque se dan numerosos sellos editoriales personales, publican además Institutos y Universidades, de manera que lo que podría ser importante a veces al carecer de un cedazo crítico lleva a la publicación de obras improvisadas. Yo que permanezco atento a estos nuevos títulos me he sentido en la incapacidad de leer muchos de ellos. De todos modos he logrado rescatar algunos títulos que sí suponen una renovación de nuestra narrativa, de nuestra poesía. Lo triste es que surgen en el vacío crítico y desaparecen lastimosamente por ausencia de ese ambiente que propician las discusiones, los debates públicos.

Este fenómeno es mundial; conozco el caso de España, donde las pequeñas editoriales, las editoriales universitarias publican textos que los llamados pulpos editoriales jamás llegarían a editar. Aquí la mujer está jugando un papel importante como narradora, filósofa, ensayista, y se ha logrado escapar del atosigante ambiente provinciano intelectual, de esa falsa escala de valores impuesta por premios amañados, por una publicidad vacía donde el libro se convierte en un hit parade. Hay que distinguir sí entre la industria del marketing comercial y la imposición heroica de la verdadera literatura, del libro de pensamiento que tiene un público devoto. Rescatemos el lema juanramoniano: "A las inmensas minorías".

\section{La divulgación y éxito de algunos escritores muchas veces parece guardar} poca relación con las calidades de sus obras. ¿Cómo ve el mercado editorial de hoy y su incidencia en las tendencias de creación y de consumo del libro?

Ante nuestros propios ojos hemos visto ascender en los cielos de la publicidad la obra de algunos escritores y los hemos visto en grandes hoteles, destacados por notas comerciales y después los hemos visto caer estrepitosa y melancólicamente hasta desaparecer y comenzar a gastarse la plata del mercado en agentes literarios 
muy caros que solamente prolongarán artificialmente la vida de este tipo de escritor zombi. Esto pertenece al mundo del marketing, y no al de la literatura propiamente, que por su poder económico continúan llevando a muchos inocentes al matadero.

La farsa del Premio Planeta con rey y reina a bordo y la farsa de abrir los sobres para saber el nombre de unos ganadores que ya se sabían de antemano demuestran hasta dónde ha podido llegar esta mentira cultural. Y los "premios" y su éxito publicitario por desgracia se convierten en modelo para quienes tratarán de obtenerlos siguiendo unas normas comerciales sin darse cuenta de que estos estereotipos van cambiando de temática y de tratamiento a gusto de esos comerciantes. No sigamos confundiendo un bestseller con un libro popular.

¿Quién recuerda hoy algún premio Alfaguara o Planeta? En España se dan hoy por lo menos mil premios al año, de manera que quien no ganó uno sigue haciendo la fila hasta que le toque. ¿Qué tal nuestros premios nacionales de literatura manipulados por burócratas y Zhdánov criollos?

\section{¿Y cómo ve la relación literatura y mercado editorial en nuestro entorno?}

Hay un gran estudio de Pascale Casanova, La República mundial de las letras, donde con inmensa lucidez y un acopio extraordinario de documentos nos ilustra sobre cómo el gran mercado editorial homogeniza la literatura al imponer modelos únicos de narración, lenguajes al uso de cualquier anodino turista y de cómo los pulpos al apoderarse de las pequeñas editoriales en España y Latinoamérica imponen unas formas de narración insaboras e incoloras al uso de las nuevas clases fariseas. En Colombia las oficinas dependientes de estos pulpos se han limitado a publicar lo que estos amos les imponen y lo que su ignorancia les dicta.

\section{Usted también ha cumplido una tarea importante como estudioso de la lite-} ratura y como crítico literario. ¿Qué rol cree que debería cumplir la crítica literaria en este contexto, y cuál rol siente que está cumpliendo esa crítica en la Colombia actual?

El Marketing tiene una misión: crear un falso presente para romper con el pasado, con esos vasos comunicantes que necesita la cultura literaria para saber que cuenta y debe responder a una tradición. Foucault o Kundera nos demuestran que Cervantes es nuestro contemporáneo, que Dante está cerca de nosotros. El padre de nuestra no- 
vela moderna es Eduardo Zalamea Borda con Cuatro años a bordo de mi mismo, quien rescata al Carrasquilla que en Frutos de mi tierra había planteado la necesidad formal de una novela que fuera capaz de captar una sociedad que había cambiado gracias a la irrupción de una economía capitalista. Los jóvenes miran hacia atrás y no ven nada, nadie les habla. Este vacío nos muestra lo terrible que resulta, como señala Steiner, la ausencia de los grandes maestros. Hernando Téllez convirtió a Proust es nuestro contemporáneo, y no digamos la tarea de modernizarnos que cumplió Sanín Cano, la tarea crítica de Valencia Goelkel, de Rafael Gutiérrez Girardot. La edad madura de toda sociedad, lo recuerda Goethe, es la presencia de la crítica.

Si le preguntáramos por los escritores colombianos contemporáneos más sobresalientes por su producción literaria, más allá del fenómeno editorial, ¿̇a quiénes destacaría, y por qué?

Sanín Cano, Fernando González y Nicolás Gómez Dávila, por su universalidad del pensamiento que se hace libre y nos impulsa a ser libres. Carrasquilla, Zalamea Borda, Rivera, García Márquez.

¿Podríamos hablar de los escritores más influyentes en su trayectoria como lector y como escritor? ¿Podríamos preguntarnos por su canon personal, por decirlo de alguna manera?

Rousseau en El Emilio supuso una educación sentimental; todo Dickens; Sthendal, Proust, Joyce, Faulkner, Kafka, Borges, Dostoievski, Thomas Wolfe, Ibsen, Becket, Pavese, y Camus por siempre.

La música ha sido otra de las protagonistas en su trayectoria. Cuéntenos un poco sobre su relación con la música y el modo como esta ha marcado el compás de su vida y en parte también de su obra poética y narrativa.

El "ante todo la música" de Mallarmé supone la necesidad de llevar adelante aquel notable propósito de Flaubert de escribir una obra sin tema, apoyado solamente en la musicalidad del texto, que es un propósito que descubrí en la lírica descripción del río desbocado en "Dos palmeras", en Del tiempo y el río de Thomas Wolfe o en la prosa deslumbrante de Julien Gracq. Música de los salones de baile popular que está en muchos de mis cuentos o música de la melancolía de la derrota de los campesinos 
desterrados. Esa música de los lugares presente en la poesía de Montale, de Pavese, de Eliot, en muchos tangos: la suave nostalgia de aquel muchacho que eternamente regresa al barrio es el flujo interno que conduce mi sangre hacia la permanente búsqueda de imágenes imposibles. El lugar ya no existe, el lugar va contigo.

La estética también ha sido importante en su trayectoria, y usted ha sido estudioso del arte; fue fundador de las Bienales de Arte y también del Centro de Investigaciones Estéticas de la Universidad Nacional de Colombia sede Medellín. ¿Podría hacernos un balance de la presencia del arte en su vida y de la trascendencia del este en su experiencia académica y literaria?

La enseñanza de la estética apunta hacia la posibilidad de ver en una obra de arte lo que nadie ha visto, lo que nos lleva a estar a solas haciéndonos saber que somos algo más que seres mortales. Sin este pequeño éxtasis es imposible pensar en acercarse a los misteriosos comunicados de esas grandes obras. He tenido la suerte de tener para mí y durante años el Museo del Prado y descubrir lentamente la grandeza de Velázquez o de Botticelli, de Brueghel, vivir arrobado de esas atmósferas únicas que me hacían sentir sin edad. Tuve entonces grandes maestros como Moreno Galván, quien me dijo un día que no me quedara escribiendo notas de arte en los periódicos ya que eran famas efímeras y lo que cuenta es prolongar la experiencia de los azules de Matisse, los bermellones de un atardecer de Tiziano o la discreta poesía de cualquier cuadro de Eladio Vélez, pero también la grandeza de Mondrian, de Rothko, etc. Walter Pater en El Renacimiento, me lo aseguró Borges, es el único crítico capaz de fundir la experiencia estética con la poesía tal como lo logra describiendo la Mona Lisa. Solamente la poesía, recuerda Gaëtan Picon, puede acercarse a la experiencia de esos deslumbramientos que nos hacen universales. Visitar muchos museos en Europa y Estados Unidos tal como lo he podido hacer es encontrar en un cuadro o una escultura que ya no volveré a ver, la infinita grandeza del genio humano.

Y a propósito de su larga trayectoria en la Universidad Nacional de Colombia, donde es profesor emérito, ¿cómo ve hoy en retrospectiva su experiencia docente y su paso por la Universidad?

Sin la universidad yo no sería nada, porque este espacio creado por la razón para la discusión de los distintos saberes tiene además la misión histórica que desde Hum- 
boldt a Husserl, Heidegger, Ortega y Gasset, Unamuno, Russell, le imprimieron bajo el lema heraclitiano de que solamente de la discrepancia nace la tolerancia. Herida muchas veces de muerte, traicionada, la Universidad sobrevive siempre a esos ataques y despierta renovada para concedernos la posibilidad de una sabiduría modesta y necesaria a cada vida de ciudadanas y ciudadanos. Repito: nací y moriré como profesor de la Universidad, y ahí, en mi retiro, sigo instalado en ese campus.

\section{Siguiendo con las retrospectivas, quisiera pedirle una evocación de la épo- ca de su adolescencia, cuando usted vivía en el entorno de la Estación Villa, tiempos en los que, tengo entendido, se destacaba "tirando paso". ¿Cómo re- cuerda la ciudad de esa época?}

Leer Dublineses y Retrato del artista adolescente de Joyce fue, deslumbrado, leer mi propia vida: borrachos, vagos, discusiones de amigos, esposas enfadadas, ese era el escenario de mi clase media en aquellas calles donde convivíamos con los derrotados convertidos en mendigos. En toda barra de amigos de barrio es necesario demostrar destrezas para defendernos de los violentos. Recorríamos la ciudad, íbamos a los teatros de otros barrios y nos hicimos virtuosos en el baile de la guaracha, del porro, porque quien no sabía bailar estaba condenado al ostracismo, no podía visitar los bailes y las muchachas. De ahí de esos temores nació el conflicto entre nuestro argot y la lengua oficial, la sensación de la pronta diáspora y la necesidad de crear con palabras nuevas ese barrio al cual nunca dejaríamos de visitar. Me crie entre la gran música en el Teatro Bolívar y la música de la Sonora Matancera, de la Orquesta Riverside.

\section{¿En qué se ocupa hoy el maestro Darío? ¿Qué podemos esperar sus lectores? ¿Hay alguna obra en ciernes?}

Mi único oficio es escribir durante todo el día, revisar una y otra vez los textos que escribo, mi columna semanal, es una tarea que en tiempos de indigencia moral, como recuerda Márai, nos ayuda a no derrumbarnos salvando las palabras de las contaminaciones ideológicas, de la erosión a que las somete la falsa literatura. Están listas dos novelas como experiencias del lenguaje y una colección de mis ensayos literarios, ya que es el ensayo un vicio inconfesable. Maestro, le preguntó Rilke a Rodin, ¿cómo ha resuelto usted el problema de la muerte? Y Rodin respondió: trabajando. No, el trabajo no fatiga. 
Ya propósito de escritura, ¿qué tan importante es la disciplina para un escritor?

Pavese dice que lo más importante en un escritor es el rigor de la disciplina que conduce al oficio de la escritura "así como se ama la vida por la vida". Y el rigor diario le permite a un escritor encontrar aquello que no buscaba en las palabras, esos reinos invisibles de la escritura que nos llevan a reconocer un magisterio y a sabernos contemporáneos de los grandes maestros "al buscar lo que ellos buscaban".

Si me permite la infidencia, quiero mencionar que la programación de esta entrevista se vio afectada por la muerte de algunos de sus seres queridos. Aprovecho para expresarle mis condolencias, y en esta coyuntura también para pedirle que cierre esta entrevista con una reflexión sobre lo que considera lo más esencial y trascendental en esta vida, su vida, ahora que llega a sus 85 años y puede hacer balance de una muy variada y prolífica trayectoria como académico y también como escritor.

A Manuel Mejía Vallejo le gustaba repetir siempre y en cualquier ocasión un verso de Barba Jacob: "contra la muerte, Coros de alegría". Y un texto bellísimo del gran Norbert Elias se llama La soledad de los moribundos. Se abre el silencio y de la mano temblorosa de un ser querido se va despidiendo la llama de la vida. Construir la presencia en la ausencia consiste en darnos cuenta de que solamente la memoria de nuestro cuerpo logrará recordar la presencia del ausente, un aroma que viene del solar, un objeto que cae en la noche, una música apenas audible, el estoicismo de mi mamá o la fija mirada de mi papá, carreras de ratones, falenas atrapadas en una telaraña. El ausente aumenta nuestra sensación de ausentes. Hablar con los muertos es hablar con las historias que nunca serán capaces de contar los libros de los archivadores.

\section{¿Hay algún otro tema al que le gustaría referirse aquí para finalizar? ¿Hacer mención de algunas personas a las que quiera dirigirse, por ejemplo?}

La cortesía de un escritor llegado a mis años tiene que ser la del retiro y el silencio. Quienes han estado cerca de mi vida ya lo saben y, como decía en una entrevista el anciano Fritz Lang, cuando ya han desaparecido los amigos lo único que queda es morir sin problema. Y con esta cortesía traigo a cuento aquello que el gran Montherlant decía: "Para escribir uno necesita pensar que es amado y que es comprendido y que uno está muerto”. Pero la vida es una exigencia y la alegría un objetivo permanente. 


\section{Referencias bibliográficas}

Ruiz Gómez, D. (1993). Cajón de sastre. Cali: Ediciones Universidad del Valle.

Ruiz Gómez, D. (1996). La ternura que tengo para vos. Medellín: Editorial Universidad Pontificia Bolivariana.

Ruiz Gómez, D. (2011). Bei den Heiden. Zurich: Edition 8.

Ruiz-Olaya, A. (2017). ¿Dónde se genera la violencia?: los personajes cotidianos y el espacio urbano en Crímenes municipales de Darío Ruiz Gómez. Mester 45 (1), pp. 133-152.

Triviño Anzola, C. (2009). La columna de Consuelo Triviño. Dario Ruiz Gómez: entender la modernidad como progreso material, además de erróneo, es peligroso. Aurora Boreal (30 de agosto). Recuperado de https://www.auroraboreal.net/actualidad/la-columna-de-consuelo-trivino/748-dario-ruiz-gomez-entender-la-modernidad-como-progreso-material-ademas-de-erroneo-es-peligroso [10.12.2021].

Valverde, U. (1996). Presentación. En D. Ruiz Gómez. La ternura que tengo para vos (pp. 7-10). Medellín: Editorial Universidad Pontificia Bolivariana. 